ORIGINAL ARTICLE

\title{
Amylin peptide levels are raised in infants of diabetic mothers
}

\author{
V Kairamkonda, A Deorukhkar, R Coombs, R Fraser, T Mayer
}

Arch Dis Child 2005;90:1279-1282. doi: 10.1136/adc.2005.078238

See end of article for authors' affiliations

......................

Correspondence to: Dr V Kairamkonda, Leicester Royal Infirmary, Neonatal Intensive Care Unit, Infirmary Square, Leicester LE1 5 WW, UK venkatash.kairamkonda@ uhl-tr.nhs.uk

Accepted

9 September 2005

Published Online First

20 September 2005
Background: Amylin is a novel 37 amino acid peptide hormone that is co-secreted with insulin from the pancreas in response to food intake. As a potent inhibitor of gastric emptying it plays an important role in the control of carbohydrate absorption. Feed intolerance is common in infants of diabetic mothers (IDM). Aims: To establish a normal range of amylin levels in healthy neonates, and to determine whether serum amylin levels are raised in IDM.

Methods: A serial sample of 221 infants $\geqslant 28$ weeks gestation was enrolled prior to delivery over a 12 month period. Blood samples collected immediately after birth (umbilical cord), and at the routine Guthrie test were analysed for amylin and insulin levels.

Results: Amylin levels in umbilical cord $(n=181)$ and Guthrie samples $(n=33)$ of healthy infants were 5.7 (3.0-9.1) and 6.9 (2.9-9.0) pmol/I respectively. IDM had significantly raised amylin levels in both cord $(\mathrm{n}=31 ; 32.7 \mathrm{pmol} / \mathrm{l}, 25.9-48.1)$ and Guthrie samples $(\mathrm{n}=8 ; 18.1 \mathrm{pmol} / \mathrm{l}, 15.3-23.6)$. Amylin correlated positively with insulin $(n=42 ; r=0.67 ; 95 \% \mathrm{Cl} 0.4$ to 0.81$)$, birth weight $(r=0.22 ; 95 \% \mathrm{Cl}$ 0.08 to 0.36 ), and gestation ( $r=0.18 ; 95 \% \mathrm{Cl} 0.03$ to 0.32$)$. Umbilical cord venous amylin levels showed agreement with arterial cord amylin levels $(n=34$, mean bias $-0.2,95 \% \mathrm{Cl} 3.1$ to -3.6$)$.

Conclusions: Amylin levels are significantly increased in the umbilical cord and Guthrie blood samples in IDM.
$\mathrm{F}$ eed intolerance is a major problem occurring in approximately $37 \%$ of infants of diabetic mothers $(\mathrm{IDM})^{1}$ and a key reason for prolongation of hospital stay and parent-infant separation. ${ }^{2}$ It is often present in the absence of prematurity, respiratory distress, and polyhydramnios, and the incidence is similar among large-forgestational-age and appropriate-for-gestational-age infants. ${ }^{2}$ The exact aetiology and pathophysiology of feed intolerance in IDM is not known.

Insight into the regulation of gastric motility has been advanced by the recent discovery of amylin, ${ }^{3}$ which is a novel 37 amino acid peptide hormone from the calcitonin gene related peptide super family. It is co-secreted with insulin from the pancreatic $\beta$ cells in response to enteral nutrient intake. ${ }^{4}$ As a potent inhibitor of gastric motility it plays an important role in the control of carbohydrate absorption by regulating the efflux from the stomach to the small bowel. ${ }^{5}$ In addition to this local effect, there is evidence to suggest that amylin has neuroendocrine effects influencing glycaemic control, satiety, and long term energy homoeostasis. ${ }^{6}$ Amylin also shares 50\% homology with calcitonin gene related peptide, which has been shown to be raised in acute inflammatory states. ${ }^{8-10}$

The diurnal profile of serum amylin levels has been established in healthy children and adults. ${ }^{11} 12$ However, normal serum amylin levels in the neonatal population have not been established. Increased amylin levels have been reported in early type 2 diabetes and in critically ill children with feed intolerance and delayed gastric emptying. ${ }^{13}{ }^{14}$

In view of the role of amylin in gastric emptying, we hypothesised that amylin levels may be raised in newborns with feed intolerance, especially IDM. The aim of this study was to determine the normal range of serum amylin levels in healthy neonates and to establish whether serum amylin levels are raised in IDM.

\section{SUBJECTS AND METHODS}

A serial sample of 221 infants was enrolled prior to delivery at a tertiary maternity hospital from March 2003 to February 2004 , over a 12 month period. This study was approved by the South Sheffield Research Ethics Committee and required formal written parental consent. Inclusion criteria were healthy infants born at a gestational age $\geqslant 28$ weeks and infants born to diabetic mothers (including gestational, insulin dependent, and non-insulin dependent diabetes mellitus). Infants with congenital anomalies and deliveries associated with chorioamnionitis or significant antenatal or labour complications were excluded. Preterm infants, ventilated for poor respiratory effort, who were clinically stable, were not excluded.

Prospective serial umbilical cord blood samples were collected immediately after birth, and at the routine Guthrie test (postnatal day 5). Guthrie samples from many of our planned recruits in the community were not feasible

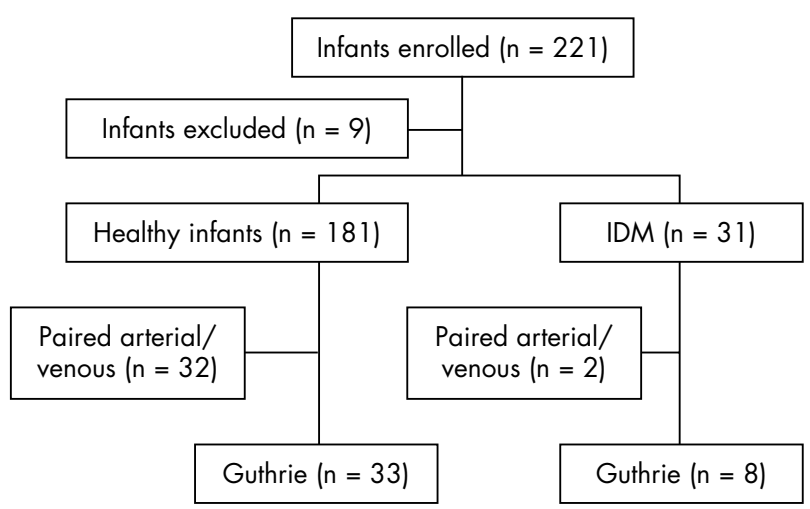

Figure 1 Distribution of blood samples. 
due to strict collection and temperature requirements for blood collection. Paired umbilical cord, venous, and arterial samples were obtained whenever possible from inpatient infants. All samples were analysed for amylin, and where volume of blood was sufficient, insulin assay was carried out to confirm co-secretion. A $1 \mathrm{ml}$ sample of blood was drawn into a tube containing EDTA with 500 IU of aprotinin; it was kept on ice before separation and storage of plasma at $-70^{\circ} \mathrm{C}$. Plasma total amylin immunoreactivity was quantified using a monoclonal antibody based sandwich immunoassay system developed by LINCO Research, Inc. (Missouri, USA). ${ }^{15}$ This has sensitivity of $1 \mathrm{pmol}$ ( $50 \mu \mathrm{l}$ plasma sample size). Interand intra-assay coefficients of variation at 50 pmol spiked concentration of amylin were $13-18 \%$ and $2.5-5 \%$ respectively. Plasma immunoreactive insulin was measured by enzyme linked immunoassay that has inter- and intra-assay coefficients of variation of $5.6 \%$ and $5.3 \%$ (BioSource Labs, Belgium).

Relevant information was retrieved from an electronic patient database. Infant data included birth weight, gestation, and gender. Maternal data included medical, antenatal, and labour history.

\section{Statistical analysis}

Statistical analysis was performed using Medcalc version 7.4.1.2 1993-2004. A priori statistical advice suggested a sample size of at least 200 observations (cord blood samples) for the calculation of a reference interval. ${ }^{16}$ To detect a difference in means of 15 and assuming a standard deviation of 13, at least 21 IDM were required (5\% two sided significance level and 90\% power). As the data were nonnormal, non-parametric tests were employed. Data are presented as median values with interquartile range (25th75th centile). Pearson's correlation coefficient was used to assess correlation between amylin and insulin levels. A p value of less than 0.05 was considered significant. A BlandAltman plot of difference between the methods ( $y$ axis) against their average (x axis) was used to measure agreement between the two sampling methods (cord arterial and cord venous) (fig 4). This method aims to investigate a possible relation between measurement error and the true value which is unknown. Therefore the mean, average discrepancy (bias), trend, and scatter of the two measurements are used as a guide to the comparability of the two methods.

\section{RESULTS}

A total of 221 infants were enrolled, of which 31 were infants of diabetic mothers. Amylin levels were analysed on venous umbilical cord blood from 181 healthy infants; nine infants were excluded from this group as cord blood obtained was unsuitable for analysis. Additional serum amylin levels were obtained from 33 of the healthy inpatient group on the fifth postnatal day (Guthrie). Among infants born to diabetic mothers $(n=31)$, Guthrie blood samples were obtained for amylin in eight infants, who were all inpatients at that time (fig 1).

Table 1 Amylin levels and demographic data of healthy infants in the cord and Guthrie groups

\begin{tabular}{lll}
\hline & Healthy infants \\
\cline { 2 - 3 } & Cord $(\mathbf{n}=181)$ & Guthrie $(\mathbf{n}=\mathbf{3 3})$ \\
\hline Amylin $(\mathrm{pmol} / \mathrm{l})$ & $5.7(3.0-9.1)$ & $6.7(2.9-9.0)$ \\
Gestation (wk) & $38(37-39)$ & $35(34-38)^{*}$ \\
Weight (kg) & $3.12(2.58-3.56)$ & $\mathbf{2 . 0 6}(1.65-3.13)^{*}$ \\
Gender (M:F) & $1.1: 1(97: 84)$ & $1: 1(17: 16)$ \\
\hline
\end{tabular}

Cord versus Guthrie (healthy infants): ${ }^{*} \mathrm{p}<0.0001$.

Values are presented as medians (25th-75th centile).
Table 2 Amylin levels and demographic data of IDM and healthy infants in the cord group

\begin{tabular}{lll}
\hline & IDM & $\begin{array}{l}\text { Healthy infants } \\
\text { Cord }(\mathbf{n}=\mathbf{1 8 1})\end{array}$ \\
\hline Amylin (pmol/l) & $\mathbf{3 2 . 7}(25.9-48.1)^{*}$ & $5.7(3.0-9.1)$ \\
Gestation (wk) & $37(34.0-39.0)$ & $38(37.0-39.0)$ \\
Weight (kg) & $3.31(2.72-3.84)$ & $3.12(2.58-3.56)$ \\
Gender (M:F) & $1.2: 1(17: 14)$ & $1.1: 1(97: 84)$ \\
\hline
\end{tabular}

IDM versus healthy infants (cord): ${ }^{*} p<0.0001$

Values are presented as medians (25th-75th centile).

In the population of healthy neonates the median cord serum amylin level was $5.7 \mathrm{pmol} / \mathrm{l}$ (3.0-9.1). A similar value was observed on the fifth postnatal day (table 1).

Median amylin level in cord blood from infants of diabetic mothers was significantly higher (32.7 pmol/l (25.9-48.1)) compared to healthy newborn infants (5.7 pmol/l (3.0-9.1)) (table 2).

In infants of diabetic mothers, the amylin levels were lower on postnatal day 5 (18.1 pmol/l (15.3-23.6)) compared to cord blood, but were still significantly higher than values in healthy neonates $(6.9 \mathrm{pmol} / \mathrm{l}(2.9-9.0))$ at the same postnatal age (table 3).

Cord serum amylin levels correlated positively with gestational age and birth weight (figs 2 and 3). Amylin levels from arterial and venous cord blood were comparable when paired samples were obtained for analysis $(\mathrm{n}=34$, $\mathrm{r}=0.98,95 \%$ CI 0.96 to $0.99, \mathrm{p}<0.0001$ ). The Bland-Altman plot (fig 4) shows the mean difference between the sampling methods to be $-0.3 \mathrm{pmol} / \mathrm{l}$ and the average discrepancy (bias) to be -0.2 . Thus the venous amylin levels tend to be lower, but despite this the limits of agreement ( -3.6 and 3.1) are small enough for us to be confident that cord arterial samples may be used interchangeably with cord venous samples for measuring amylin levels. Finally, a positive correlation was observed between amylin and insulin levels $(\mathrm{n}=42, \mathrm{r}=0.67,95 \%$ CI 0.4 to $0.81, \mathrm{p}<0.0001)$.

\section{DISCUSSION}

Amylin is co-secreted with insulin and is a potent inhibitor of gastric motility. ${ }^{5}$ High serum amylin levels have been reported in early type 2 diabetes $^{13}$ and critically ill children ${ }^{14}$ with feed intolerance. The diurnal profile of serum amylin levels has been established in healthy children ${ }^{11}$ and adults. ${ }^{12}$ This is the first study to establish the normal range of serum amylin in healthy neonates at birth and at the fifth postnatal day. The serum amylin levels in healthy neonates in our study ( $5.7 \mathrm{pmol} / \mathrm{l})$ correspond to those observed (mean (SD)) in the paediatric $(5.0$ (1.94) $\mathrm{pmol} / \mathrm{l})$ and adult $(5.0(0.4)$ pmol/l) populations. ${ }^{11}{ }^{12}$ It is possible that the cord amylin levels represent transplacental passage of this peptide. Although feasible, this seems unlikely as there was no fall in serum amylin levels by the fifth postnatal day in healthy infants when compared to levels obtained at birth. The high

Table 3 Amylin levels and demographic data of IDM and healthy infants in the Guthrie group

\begin{tabular}{lll}
\hline & $\begin{array}{l}\text { IDM } \\
\text { Guthrie }(\mathbf{n = 8})\end{array}$ & $\begin{array}{l}\text { Healthy infants } \\
\text { Guthrie }(\mathbf{n}=33)\end{array}$ \\
\hline Amylin (pmol/l) & $\mathbf{1 8 . 1}(15.3-23.6)^{*}$ & $6.9(2.9-9.0)$ \\
Gestation (wks) & $35(33-36)$ & $35(34-38)$ \\
Weight (kg) & $2.94(1.97-3.56)$ & $2.06(1.65-3.13)$ \\
Gender (M:F) & $1.6: 1(5: 3)$ & $1: 1(17: 16)$ \\
\hline
\end{tabular}

IDM versus healthy infants (Guthrie): * $p<0.0001$.

Values are presented as medians (25th-75th centile). 


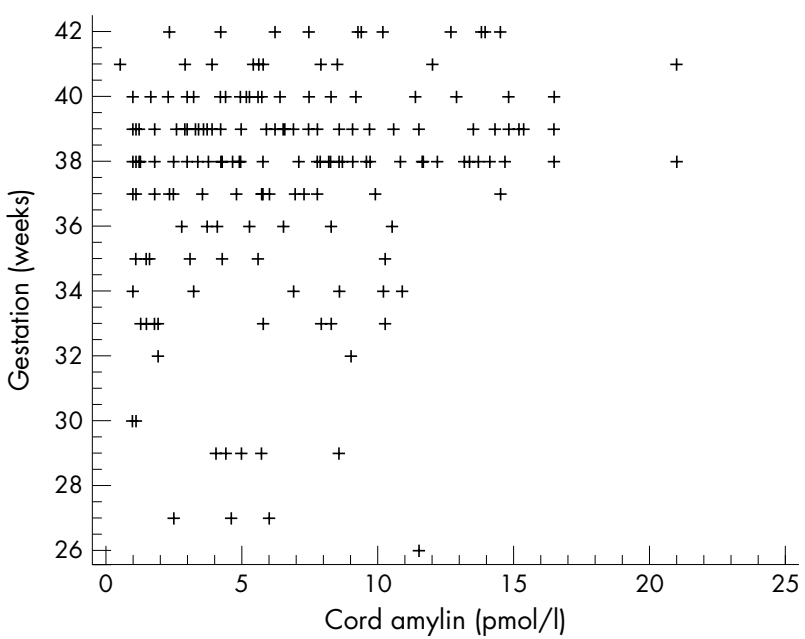

Figure 2 Correlation between cord amylin and gestation $(n=181)$. $\mathrm{r}=0.20,95 \% \mathrm{Cl} 0.04$ to $0.35, \mathrm{p}=0.012$.

amylin levels in IDM further support the theory that transplacental passage does not occur as serum amylin levels are subnormal in diabetic patients. ${ }^{311} 1718$ Thus these high levels obtained in IDM would seem to represent endogenous amylin production. Additionally studies performed in perfused human placenta with pramlintide, a synthetic analogue of amylin, indicate that pramlintide has low potential (ratio $>1000$ ) to cross the maternal/fetal placental barrier (personal communication with Amylin Pharmaceuticals, Inc., USA). The normal decay time and metabolism of natural amylin is unknown. Information gained from pramlintide studies $\left(t_{1 / 2}=50\right.$ minutes $)$, which is primarily metabolised by the kidneys after subcutaneous dosing, would further question transplacental passage being responsible for the observed serum amylin levels. In summary, this evidence would suggest that the serum amylin levels in the neonatal period are due to endogenous production, and are in the range reported in the paediatric and adult populations.

In this study serum amylin levels obtained from cord blood were significantly raised in infants born to diabetic mothers. These levels are comparable to those reported in critically ill children with feed intolerance. ${ }^{14}$ We suggest that these high serum amylin levels observed in IDM may be partially responsible for the feed intolerance seen in this population. This is in keeping with the physiological action of amylin, as it is 15-20 times more potent than other known inhibitors of gastric motility. ${ }^{19}$ There are a number of possible explanations for such high levels observed in IDM. Amylin is deficient in type 1 diabetes mellitus and is present in excess in conditions in which insulin is hyper-secreted, for example in insulin resistance states. ${ }^{4}$ It would therefore seem plausible that transient neonatal hyperinsulinaemia in IDM due to in utero exposure to maternal hyperglycaemia, may also stimulate an increase in release of endogenous amylin. This is further supported by evidence of co-secretion of amylin and insulin, shown by the positive correlation between amylin and insulin in our study ( $\mathrm{n}=42, \mathrm{r}=0.67,95 \%$ CI 0.4 to $0.81, \mathrm{p}<0.0001$ ) and previous studies. ${ }^{4}{ }^{14}$ Unfortunately we were unable to obtain sufficient sample volume for analysis of paired amylin and insulin on the fifth postnatal day.

Amylin has been shown to have both vasodilator ${ }^{20}$ and anti-inflammatory ${ }^{21}$ properties. It shares $50 \%$ homology with calcitonin gene related peptide, which is recognised to be raised in acute inflammatory states such as trauma, ${ }^{8}$ sepsis (neonatal and adult), ${ }^{9}$ and hypotensive shock. ${ }^{10}$ We therefore

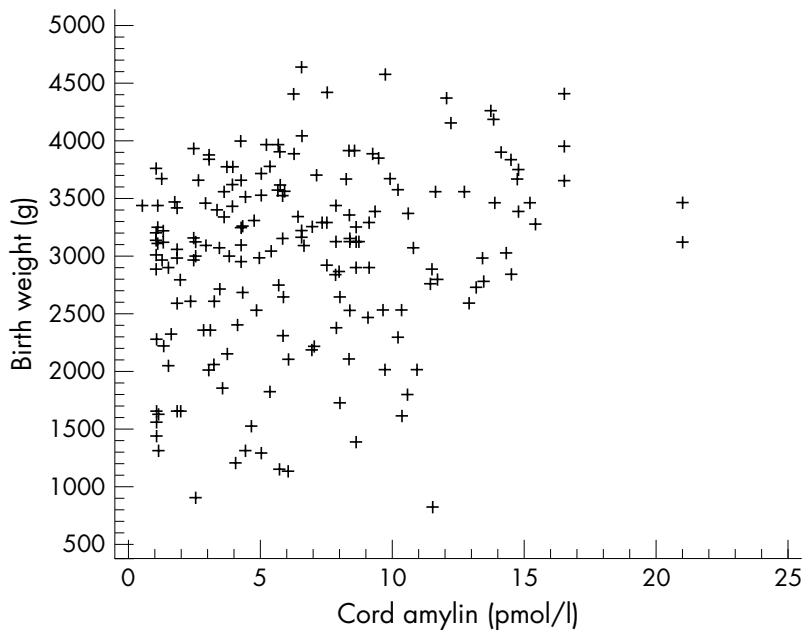

Figure 3 Correlation between cord amylin and birth weight $(n=181)$. $r=0.21,95 \% \mathrm{Cl} 0.05$ to $0.36, p=0.002$.

excluded infants born to mothers with chorioamnionitis and those with significant antenatal and labour complications.

In IDM, the fifth postnatal day amylin levels were lower than cord samples at birth. This gradual decline possibly represents absence of the hyperinsulinaemic environment and would coincide with the time course of resolution of the feed intolerance observed in IDM. However, our study did not attempt to correlate amylin levels with objective measures of gastric emptying and feed intolerance or its resolution. This is an important limitation of our study. The observed serum amylin levels in IDM at the fifth postnatal day were still above our proposed normal range for healthy infants. In retrospect, samples over a longer time period may have been useful and should be considered in the design of future studies.

Infants in the Guthrie group were lighter in weight and of a lower gestational age than in those in cord blood group. This is possibly due to a selection bias towards blood collection of inpatient neonates.

Agreement was shown between paired cord arterial and venous amylin levels; therefore either of the two methods could be used to measure amylin. This observation will help in future studies involving umbilical blood sampling.

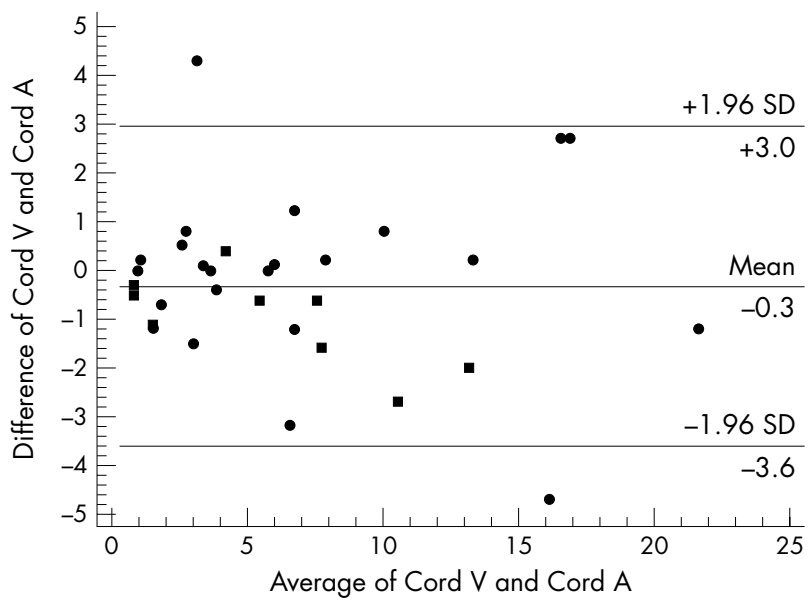

Figure 4 Method comparison (Bland-Altman) of paired venous and arterial levels. $n=34$, mean bias -0.2 , limits of agreement 3.1 to -3.6 . 


\section{What is already known on this topic}

- Although feed intolerance is common in infants of diabetic mothers (IDM), its aetiology and pathophysiology is not known

- Amylin is a novel 37 amino acid peptide hormone from the calcitonin gene related peptide superfamily, and a potent inhibitor of gastric emptying

We observed a direct correlation between amylin levels with ascending birth weight and gestation. A similar finding has been reported with the calcitonin gene related peptide. ${ }^{9}$ The significance of this observation is unclear.

The results of this study will be useful for the ongoing study investigating the role of amylin in preterm infants with feed intolerance. Amylin has been shown to be raised in rat intestinal ischaemic injury, ${ }^{22}$ and may have a biologic role in sepsis. ${ }^{9}$ Future research in the role of amylin in necrotising enterocolitis and sepsis in the neonatal population may benefit from normal values established by our study. AC187 is a truncated amylin peptide antagonist that acts by selectively and potently blocking amylin receptors. ${ }^{23}$ The biological actions of amylin in IDM and preterm infants with delayed gastric emptying need to be elucidated prior to evaluation of pharmacological blockade of this peptide as a potential therapeutic option.

In conclusion, we have established a normal range for amylin levels in neonatal population and presented evidence in support of our hypothesis that amylin levels are raised in IDM.

\section{ACKNOWLEDGEMENTS}

The authors would like to acknowledge the contributions to this study by Catherine Bruce and Manas Datta

\section{Authors' affiliations}

V Kairamkonda, A Deorukhkar, R Coombs, Dept of Neonatal Intensive Care, Royal Hallamshire Hospital, Sheffield, UK

R Fraser, Dept of Obstetrics \& Gynaecology, Royal Hallamshire Hospital, Sheffield, UK

T Mayer, Dept of Paediatric Intensive Care, Sheffield Children's Hospital, Sheffield, UK

Funding: The principle investigator was funded by the baby fund at the Jessop Wing, Royal Hallamshire Hospital, Sheffield, UK. The study sponsors had no role in the study design, in the collection, analysis, and interpretation of data, in the writing of the report, and in the decision to submit the paper for publication.

Competing interests: none declared

\section{REFERENCES}

1 Kitzmiller JL, Cloherty JP, Younger MD, et al. Diabetic pregnancy and perinatal morbidity. Am J Obstet Gynecol 1978;131:560-80.

\section{What this study adds}

- The study has presented evidence in support of the hypothesis that amylin levels are raised in IDM

- The study has also established a normal range for serum amylin in the neonatal period that would be useful for studies investigating the role of amylin in feed intolerance, necrotising enterocolitis, and sepsis in the neonatal population

2 Lee-Parritz, Cloherty JP. Maternal conditions that affect the fetus: diabetes mellitus. In: Cloherty JP, Eichenwald EC, Stark AR, eds. Manual of neonatal care, 5th edn. Philadelphia, PA: Lippincott Williams \& Wilkins, 2004:9-19.

3 Koda JE, Fineman M, Rink TJ, et al. Amylin concentrations and glucose control. Lancet 1992;339:1179-80.

4 Rink TJ, Beaumont K, Koda J, et al. Structure and biology of amylin. Trends Pharmacol Sci 1993;14:113-18.

5 Macdonald IA. Amylin and the gastrointestinal tract. Diabet Med 1997:14:S24-8.

6 Rushing PA. Central amylin signalling and the regulation of energy homeostasis. Curr Pharm Des 2003;9:819-25.

7 Bronsky J, Chada M, Kotaska K, et al. Amylin-its physiological role in humans. Cesk Fysiol 2002;51:176-80.

8 Onuoha GN, Alpar EK. Calcitonin gene-related peptide and other neuropeptides in the plasma of patients with soft tissue injury. Life $\mathrm{Sci}$ 1999;65:1351-8

9 Parida SK, Schneider DB, Stoss TD, et al. Elevated circulating calcitonin gene-related peptide in umbilical cord and infant blood associated with maternal and neonatal sepsis and shock. Pediatr Res 1998:43:276-82.

10 Joyce CD, Fiscuss RR, Wang X, et al. Calcitonin gene-related peptide levels are elevated in sepsis. Surgery 1990;108:1097-101.

11 Akimoto K, Nakazato M, Matsukura S, et al. Plasma concentration of islet amyloid polypeptide in healthy children and patients with insulin-dependent diabetes mellitus. Acta Paediatr 1993:82:310-11.

12 Mitsukawa T, Takemura J, Asai J, et al. Islet amyloid polypeptide response to glucose, insulin, and somatostatin analogue administration. Diabetes 1990;39:639-42.

13 Hoppener JW, Ahren B, Lips CJ. Islet amyloid and type 2 diabetes mellitus. NEngl J Med 2000;343:411-19.

14 Mayer AP, Durward A, Turner C, et al. Amylin is associated with delayed gastric emptying in critically ill children. Intensive Care Med 2002;28:336-40.

15 Percy A, Rittenhouse J, Trainor D, et al. Development of sensitive immunoassays to detect amylin and amylin-like peptides in untreated plasma. Clin Chem 1996;42:576-85

16 Altman DG, ed. Practical statistics for medical research. London: Chapman and Hall, 1991:423.

17 Sanke T, Hanabusa T, Nakano Y, et al. Plasma islet amyloid polypeptide (amylin) levels and their responses to oral glucose in type-2 (non-insulindependent) diabetic patients. Diabetologia 1991;34:129-32.

18 Ludvik B, Lell B, Hartter E, et al. Decrease of stimulated amylin release precedes impairment of insulin secretion in type II diabetes. Diabetes 1991;40:615-19.

19 Young A. Role of amylin in nutrient intake-animal studies. Diabet Med 1997; 14(suppl 2):S14-18.

20 Hall JM, Brain SD. Interaction of amylin with calcitonin gene-related peptide receptors in the microvasculature of hamster cheek pouch in vivo. Br J Pharmacol 1999; 126:280-4

21 Clementi G, Caruso A, Cutuli VM, et al. Anti-inflammatory activity of amylin and CGRP in different experimental models of inflammation. Life $\mathrm{Sci}$ 1995;57:L193-7.

22 Phillips AR, Abu-Zidan FM, Farrant GJ, et al. Plasma amylin concentration is related to the severity of intestinal ischemic injury in rats. Surgery $2001 ; 129: 730-5$.

23 Young AA, Gedulin B, Gaeta LSL, et al. Selective amylin antagonist suppresses rise in plasma lactate after intravenous glucose in the rat. Evidence for the metabolic role of endogenous amylin. FEBS Lett 1994;343:237-41. 